\title{
Los marcadores inflamatorios en la angina inestable también predicen mortalidad a largo plazo
}

Markers of myocardial damage and inflammation in relation to long-term mortality in unstable coronary artery disease. FRISC Study Group. Fragmin during Instability in Coronary Artery Disease. Lindahl B, Toss H, Siegbahn A, et al. N Engl J Med 2000; 343:1139-47

\section{Objetivo}

Comparar la utilidad de los marcadores inflamatorios troponina $\mathrm{T}(\mathrm{TnT})$, proteina C-reactiva (CRP), y fibrinógeno ( $\mathrm{Fn})$, como predictores de riesgo cardiovasclar a largo plazo en pacientes con angina inestable.

Diseño

Seguimiento prospectivo luego de un ensayo clínico controlado aleatorizado.

Lugar

13 Hospitales Universitarios en Suecia

\section{Pacientes}

Se incluyeron 907 pacientes con angina inestable con cambios electrocardiográficos de un estudio aleatorizado sobre heparina subcutánea de bajo peso molecular contra placebo (FRISC). Todos los pacientes tenían al inicio datos completos sobre los marcadores : TnT, CRP y Fn. Se realizó un seguimiento promedio de 2 años.

\section{Evaluación de Factores de Riesgo}

Más allá de los factores de riesgo convencionales, se evaluaron los niveles de PCR y Fn al inicio y el pico máximo de TnTdurante las primeras 24 hs. Un comité analizó independientemente los eventos en el seguimiento. Como no hubo diferencias de mortalidad en las dos ramas del estudio aleatorizado se fusionaron ambas en una sola cohorte para el análisis del valor pronóstico de los marcadores. El punto final fue mortalidad por causa cardíaca a los dos años de seguimiento.

\section{Resultados}

Al mes, al año y a los dos años la mortalidad de la cohorte fue de $1.7 \%, 6.7 \%$ y $9.5 \%$ respectivamente.

En el seguimiento, el $1.2 \%$ de los pacientes con TnT $<0.06$ microgs/L fallecieron por causas cardíacas, en comparación al $8.7 \%$ de pacientes con valores entre 0.06 y 0.59 microg $/ \mathrm{L}$, y $15.4 \%$ de los que tenían valores de 0.60 microg/L o más $(p<0.005)$. La mortalidad cardíaca fue del $5.7 \%$ en los pacientes con PCR $<2 \mathrm{mg} / \mathrm{L}$, $7.8 \%$ en los que tenían de 2 a $10 \mathrm{mg} / \mathrm{Ly} 16.5 \%$ entre los que tenían más de $10 \mathrm{mg} / \mathrm{L}$. En el análisis multivariado* la elevación de TnT se asoció con muerte cardíaca con un RR de 6.8 (IC95\% 1.6028.2) y de 11.3 (IC95\% 2.7-46.4) para 0.06-0.59 y > de $0.60 \mathrm{ng} / \mathrm{ml}$ de $\mathrm{TnT}$ respectivamente. Los pacientes que murieron de causas cardíacas presentaron niveles más altos de CPR y Fn que los sobrevivientes (13 vs $5 \mathrm{mg} / \mathrm{l}, \mathrm{p}<0,001$ y 3.9 vs $3,6 \mathrm{mg} / \mathrm{l}, \mathrm{p}<0.01$ ). Los pacientes con los niveles más altos de CRP (>10 mg/l) tuvieron más alta probabilidad de muerte cardíaca que los que presentaron valores intermedios (2-10 mg/l) y bajos (<2 mg/l). El RR para $>10$ fue 2.6 (IC95\% 1.5-4.5). El RR para los niveles de Fn de más de 4 fue 2.3 (IC95\% 1.3-4.1). En el análisis multivariado*, tanto los niveles de tnT y CRP fueron predictores independientes de riesgo de muerte cardíaca.

\section{Conclusiones}

En la enfermedad coronaria inestable, los niveles elevados de troponina $T$ y proteina $C$ reactiva estuvieron fuertemente asociados al riesgo a largo plazo de muerte cardiovascular. Estos marcadores fueron factores de riesgo independientes, y sus efectos fueron aditivos entre ellos y a otros factores de riesgo cardiovasculares.

\section{Comentario}

La troponina es un marcador de injuria miocárdica debida a microembolización y se considera un marcador de una placa activada con trombo'. Los reactantes de fase aguda como la CRP, el Fn y otros son marcadores de inflamación que acompañan al fenómeno agudo de placa. Ambos han sido propuestos recientemente como índices pronósticos que eleven la eficiencia de la evaluación tradicional realizada por la clínica y el ECG ${ }^{2} 3$. Se sabe que este esquema tiene una tasa de falsos negativos de 2 a $3 \%$ (pacientes coronarios que son dados de alta) y un número elevado de falsos positivos (pacientes que se internan en unidades de cuidado intensivo o de dolor torácico que no tienen enfermedad coronaria); esto último conduce a un exceso de uso de recursos innecesarios. Este estudio es importante porque avanza en la caracterización pronóstica de estos marcadores y confirma algo ya conocido: la troponina de ingreso es un poderoso marcador de riesgo y probablemente deba recomendarse en sustitución de la CPK-MB. La CRP de ingreso parece un marcador más débil y quizás adquiera mayor poder a medida que avanzan los días. Otra importante colaboración de este estudio es que apoya la teoría del efecto aditivo del uso de marcadores con diferente sustrato fisiopatológico. Esto está en concordancia con datos propios y de otros grupos 4 . La limitación de este estudio radica en que es una población altamente seleccionada, derivada de una forma, quizás no muy ortodoxa, de un estudio aleatorizado para estudiar una estrategia terapéutica. Los datos que están haciendo más falta son los que provienen de estudios epidemiológicos sin pacientes tan seleccionados.

\section{Referencias}

1. Hamm CW, Ravkilde J, Gerhardt W, et al. The prognostic value of serum troponin Tin unstable angina. N Engl J Med 1992;327:146-50

2. Maseri A, Liuzzo G, Biasucci LM. Pathogenic mechanisms in unstable angina. Heart 1999;82:Suppl 1:12-14

3. Toss H, Lindhal B, Siebhan A. Prognostic influence of increased fibrinogen and C- reactive protein levels in unstable corobary artery disease. Circulation 1997;96:4204-10

4. Holmvang L, Luscher MS, Clemmensen P, et al. Very early risk stratification using combined Ecg and biochemical assesment in patients with unstable coronary artery disease. Circula tion 1998;98: 2004-9 